\title{
Estimating cost savings by introducing a reflex hepatitis $B$ virus screening algorithm in a sexual health service
}

Bradshaw $\mathrm{D}^{1,2}$, Muir $\mathrm{D}^{3}$, Rayment $\mathrm{M}^{1}$

1. Chelsea and Westminster Hospital NHS Foundation Trust 2. Brighton and Sussex University Hospitals NHS Trust 3. Imperial College Healthcare NHS Trust

\section{Introduction}

BASHH recommends that screening for HBV may be with anti-HBV core antibody (HBcAb), with reflex HBV surface antigen (HBsAg) testing in HBcAb-positive patients (Fig 1). False negative HBcAb (eg in acute HBV infection or with low assay sensitivity) is rare. At the time, our screening strategy for hepatitis B was to request both $\mathrm{HBsAg}$ and $\mathrm{HBCAb}$ simultaneously, rather that opting for reflex $\mathrm{HBsAg}$ testing on $\mathrm{HBcAb}$ positive samples (with redundant $\mathrm{HBsAg}$ tests being performed in the presence of a negative $\mathrm{HBCAb}$ ). We wished to audit the extent of this practice and estimate cost savings by introducing reflex testing.

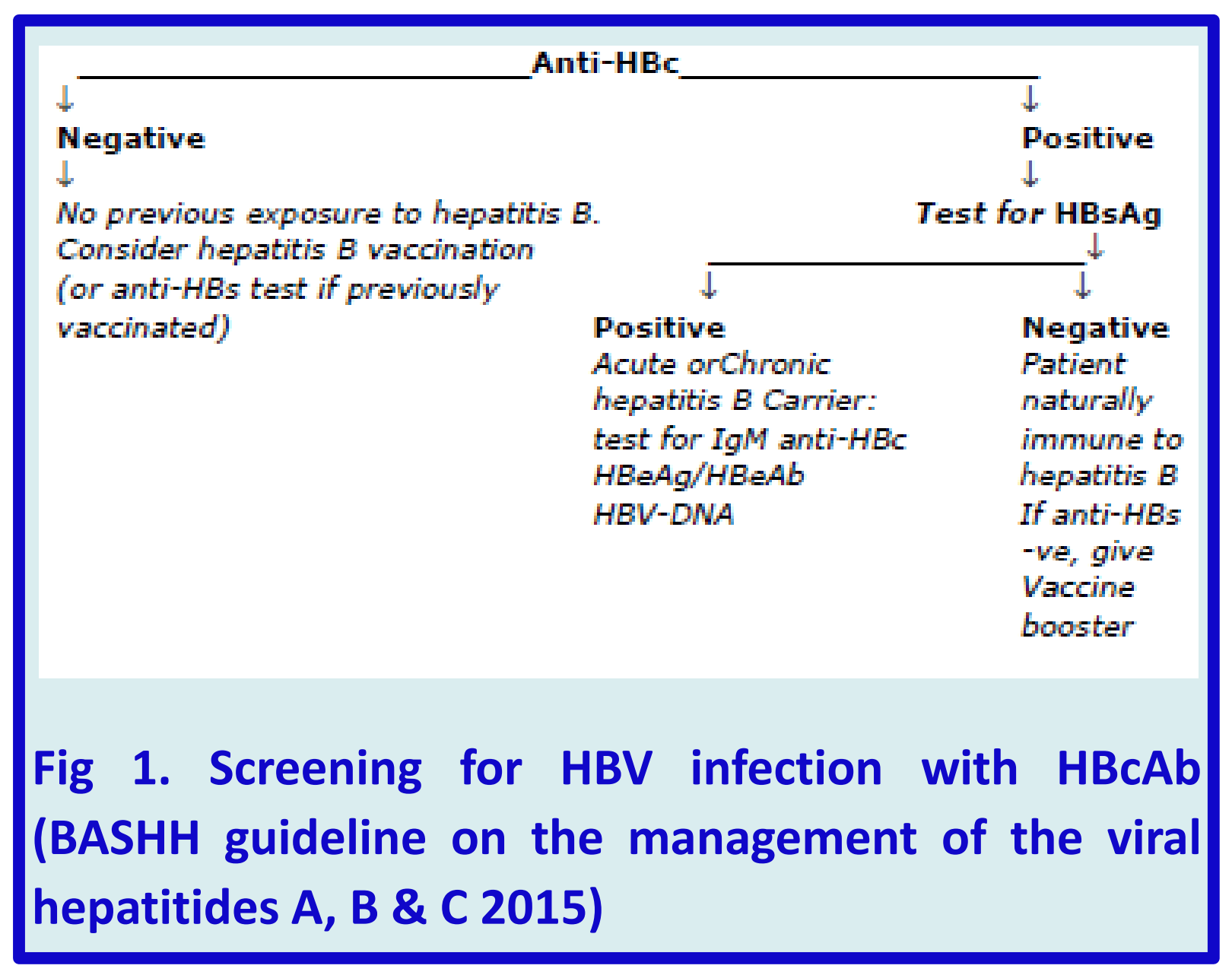

\section{Methods}

This was a retrospective case notes review of patients for whom $\mathrm{HBCAb}$ had been requested between 01/01/15 and 01/05/15. The cost of performing $\mathrm{HBsAg}$ testing was estimated at $£ 3.60$ per test.

\section{Results}

There were two hundred patients with $\mathrm{HBcAb}$ results: 110 (55\%) male; median age 32 (IQR 26-39) years; 9 (4.5\%) HIV-infected. Twenty-two (11\%) tested HBcAb-positive of whom 5 (2.5\%) were HBsAg-positive, 16 (8.0\%) HBsAg-negative and 1 (0.5\%) not tested for HBsAg (Fig. 2).
Of the HBcAb-positive individuals, requesting details were available for 10 cases: for $8 / 10$ both $\mathrm{HBsAg}$ and $\mathrm{HBcAb}$ were requested initially. Of 178 (89.0\%) HBcAb-negative individuals, HBsAg was performed for 49 (24.5\%); all were HBsAg-negative.

Across the Trust, $11,500 \mathrm{HBcAb}$ tests were requested in 12 months. Assuming $89.0 \% \mathrm{HBcAb}$ negativity, the cost of testing $24.5 \%$ of these patients for HBsAg would almost reach $£ 10,000$.

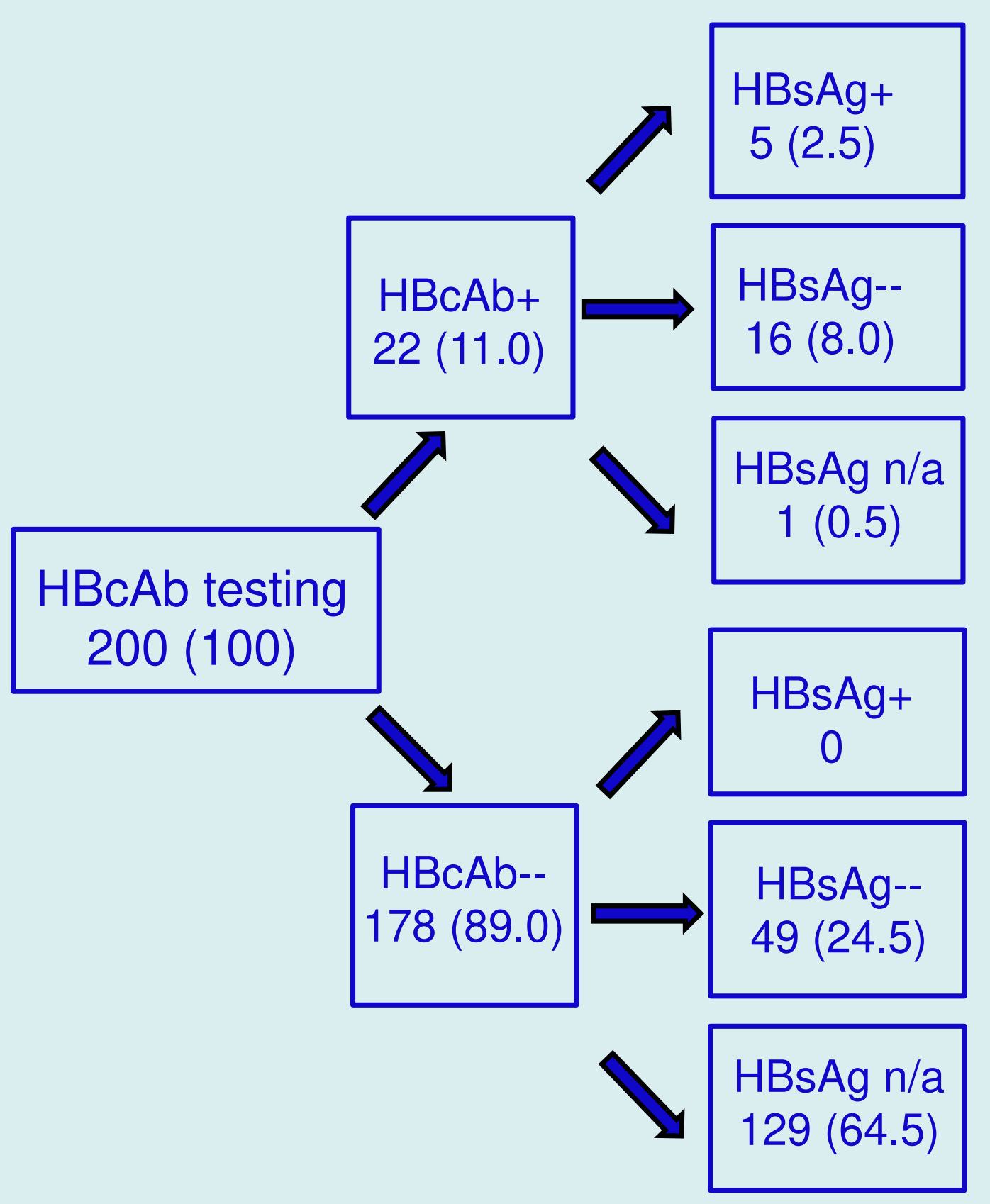

Fig. 2. Identification of HBV-infected patients following screening with $\mathrm{HBCAb}$ Brackets indicate \%

\section{Conclusions}

Reducing $\mathrm{HBsAg}$ testing in $\mathrm{HBcAb}$ negative individuals would provide savings. Reflex laboratory HBsAg should be implemented for HBcAb-positive patients. 